\title{
La Experiencia de la Evaluación Docente en México: Análisis Crítico de la Imposición del Servicio Profesional Docente
}

\author{
The Experiencie of Teacher Evaluation in México: Critical \\ Analysis of the Imposition of the Profesional Teaching Service
}

\author{
Francisco Guzmán Marín * \\ Universidad Pedagógica Nacional (UPN) - México
}

\begin{abstract}
La Evaluación Educativa representa una cultura, práctica y política institucional bastante tardía en el avance y fortalecimiento de la educación formal en México, pues, antes de la década de los 80’s era casi inexistente en nuestro país; mientras que, por su parte, la Evaluación del Desempeño Docente en la educación obligatoria, constituye una de las áreas con menor grado de desarrollo en el Sistema Educativo Nacional, con respecto a la amplia experiencia generada en el contexto internacional. En las últimas tres décadas, el gobierno mexicano se ha empeñado en imponer la evaluación docente como una estrategia política que comprende tres principales objetivos, a saber: recuperar la rectoría del Estado en materia educativa, elevar la calidad de los servicios públicos de educación y establecer dispositivos administrativo-laborales de control sobre el ingreso, permanencia, promoción y reconocimiento en el Servicio Profesional Docente. El presente artículo expone un primer avance de investigación histórico-educativa, desde la perspectiva del enfoque genealógico nietzscheano-foucaultiano, sobre la experiencia de la evaluación docente construida en México, cuyos primeros resultados muestran ya que las políticas, instancias e instrumentos de evaluación del magisterio, impuestas por las autoridades educativas de las últimas tres décadas, no sólo resultan excesivamente onerosas sino que, además, son inconsistentes frente a los modelos y estrategias de evaluación implementadas por los sistemas educativos con mayor rendimiento académico e impertinentes al propósito manifiesto de elevar la calidad de los servicios de educación en el país.
\end{abstract}

Palabras Clave: Educación; Evaluación docente; Profesores; Reforma educativa; Calidad educativa.

The Educational Evaluation represents a rather late culture, practice and institutional policy in the advancement and strengthening of formal education in Mexico, since, before the Decade of the 80's, it was almost non-existent in our country; while, furthermore, the Evaluation of Teaching Performance in compulsory education, is one of the 135isto with lower degree of development in the national education system, with respect to the experience generated in the international context. In the last three decades, the Mexican Government has endeavored to impose the teaching evaluation as a political strategy that includes three main objectives, namely: recover the rectory of the State in education, raise the quality of services public education and to establish administrative control devices on admission, permanence, promotion and recognition devices in the Professional Educational Service. This article exposes a first advance of 135istórico-educativa research, from the perspective of the genealogical approach Nietzschean-Foucauldian, on the experience of teaching evaluation built in Mexico, whose first results show that policies, instances and instruments of teacher evaluation, imposed by the educational authorities of the past three decades, they are not only excessively onerous, but that they are also inconsistent with models and strategies of evaluation implemented by educational systems with higher academic performance and impertinent to the manifest purpose of raising the quality of education in the country services.

Keywords: Education; Teacher evaluation; Teachers; Educational reform; Educational quality.

*Contacto: coraxthelastone@hotmail.com

issn: 1989-0397

www.rinace.net/riee/

https://revistas.uam.es/riee
Recibido:

31 de enero de 2018

$1^{\text {a }}$ Evaluación: 23 de febrero de 2018

Aceptado: 13 de marzo de 2018 


\section{"Es claro que la evaluación docente por sí misma no puede garantizar que un país cuente con profesores bien preparados, si antes no han existido procesos robustos de formación inicial y de formación continua."}

(Eduardo Backhoff Escudero / Gilberto Guevara Niebla)

\section{Introducción General}

La Evaluación Educativa representa una cultura, práctica y política institucional bastante tardía en el avance y fortalecimiento de la educación formal en México, pues, antes de la década de los 80's era casi inexistente en nuestro país, como bien apunta Vidal (2009); mientras que, por su parte, la Evaluación del Desempeño Docente en la educación obligatoria, constituye una de las áreas con menor grado de desarrollo en el Sistema Educativo Nacional, a decir de Garduño (2005), con respecto a la amplia experiencia internacional, puesto que en otras naciones y regiones del mundo se viene realizando con diferentes marcos de referencia y niveles de logro, a lo largo del siglo XX -tal como sucede en los Estados Unidos de América, Cuba y Europa, por ejemplo; y aún antes del predominio del denominado neo-liberalismo en el orden global, hacia el año de 1917 en la república caribeña, de acuerdo con Valdés (2001)1-; sin embargo, ambos procesos, pero, sobre todo el último, significan factores emergentes de un vasto debate, desconfianza, escisión y resistencia empecinada, en la compleja comunidad socio-educativa mexicana, sobre todo porque los responsables directos de su diseño, arraigo y aplicación, desde la Dirección General de Evaluación (DGE), en 1984, hasta el Instituto Nacional para la Evaluación de la Educación (INEE) y la propia Secretaría de Educación Pública (SEP), en los albores del siglo XXI, han carecido de la sensibilidad y habilidad política necesaria para su instauración estandarizada y general, en la diversa composición de la estructura educativa del país.

De hecho, a tres lustros de promover la evaluación sistemática de los docentes de Educación Básica y Media Superior (EMS), y después de la experiencia construida por los recientes modelos precedentes en este campo -a saber: Carrera Magisterial y el Programa de Estímulos a la Calidad Docente-, con la imposición institucional del Servicio Profesional Docente (SPD), en la comunidad magisterial mexicana, todavía prevalecen profundas confusiones sobre los propósitos, el paradigma, los criterios, mecanismos operativos e implicaciones laborales de tal estrategia de evaluación, esto sin olvidar, el verdadero impacto que han tenido los resultados de evaluación docente en la pretendida calidad del servicio educativo, por mencionar sólo algunos de los aspectos más relevantes al respecto.

Ante la insuficiente y confusa información oficial respecto del modelo de evaluación del desempeño docente que aplica el INEE, su función institucional en el Sistema Educativo Nacional y las auténticas implicaciones laborales que comporta para el magisterio mexicano, la discusión entre el Gobierno Federal, los especialistas del ramo y los profesores agrupados en la disidencia sindical, se reduce a tres principales puntos, tales son: el presunto origen neoliberal de las políticas educativas gubernamentales, el carácter

\footnotetext{
${ }^{1}$ Héctor Valdés Veloz es Ex-director del Instituto Central de Ciencias Pedagógicas en Cuba.
} 
educativo o laboral-administrativo de la reforma y la legitimidad de los procesos estandarizados de evaluación, soslayando el abordaje crítico-analítico sobre la pertinencia y oportunidad de instaurar las estrategias de evaluación docente como un factor definitorio de la reorientación histórica de las acciones de formación del profesorado, el mejoramiento de la calidad educativa y la regulación de los procedimientos de ingreso, permanencia y promoción al SPD, con el consecuente fortalecimiento de las estructuras institucionales que sustentan a la educación pública.

\section{Principales Enfoques de Evaluación Docente}

La evaluación docente, según sucede con todo tipo de evaluación, se encuentra determinada por el objeto, los propósitos, los dispositivos procedimentales, los instrumentos, los momentos y los agentes de ponderación efectiva, traducido eso en términos de interrogación, las cuestiones son: ¿qué se evalúa?, ¿̨para qué se evalúa?, ¿cómo se evalúa?, ¿̇con qué se evalúa?, ¿̇cuándo se evalúa? y ¿̇quiénes evalúan?; de manera general, a su vez, Stake (2006) plantea como preguntas centrales: ¿cuál es la calidad del evaluando? y ¿cuáles son las principales percepciones que se tienen de su calidad? La forma de abordar cada una de estas interpelaciones y el propio conjunto de respuestas que se proyectan al respecto, constituyen los distintos enfoques de evaluación, predominantes en los Sistemas Educativos del mundo contemporáneo. Es cierto, como bien advierte Moreno (2011), que nos encontramos en una "época marcada por constantes evaluaciones" (p. 116), se demanda que todo sea evaluado de forma permanente, ya en cuanto estrategia de fiscalización y transparencia pública, o bien en tanto instrumento de control administrativo y fuente de identificación de las áreas de mejora de cualquier fenómeno social, pero, en razón de esto mismo, es verdad, también, que el diseño, aplicación, procesamiento e interpretación de los resultados en los procesos de ponderación, pueden deformar la naturaleza y percepción del fenómeno evaluado. De hecho, Hanson (1994) considera que por su misma existencia, las pruebas modifican e incluso crean lo que se pretende evaluar. No es fortuito que en más de las ocasiones deseadas y aceptadas por los agentes evaluadores, los resultados de la evaluación tan sólo reflejen las insuficiencias de la misma, más que del objeto evaluado.

En esta perspectiva, a su vez, el modo específico en que se dispongan los dispositivos institucionales de evaluación y el uso concreto que se hagan de sus resultados, la puede convertir en un factor estratégico del desarrollo del fenómeno valorado, según parece suceder con la evaluación docente en los sistemas con mayor desempeño educativo, pero, también al contrario, es posible emplazarla en cuanto mecanismo de control y/o coerción socio-política y administrativo-laboral, como acusan los detractores del SPD, en México; cuestión ya anticipada por Beck (2007) y Landínez (2011), a los cuales se suma las reflexiones de Valdés (2001), quien sin ambages declara:

\section{La evaluación puede utilizarse para impulsar la realización profesional, la autonomía y la colaboración entre los docentes, o bien puede invertirse y promover recelos, miedos y rechazo expreso del profesorado debido a las desviaciones de que pueda ser objeto la evaluación y sus consecuencias para los docentes. (p. 2)}

En esta misma perspectiva, resulta pertinente señalar, siguiendo a Santos Guerra (2003a, 2003b), que la evaluación siempre comporta un factor moral, definida por los valores a que responde, los agentes beneficiados y las causas a las cuales sirve -"La evaluación, además de ser un proceso técnico es un fenómeno moral. Importa mucho saber a qué valores sirve 
y a qué personas beneficia. Importa mucho evaluar bien, pero importa más saber a qué causas sirve la evaluación”, según explica el especialista español (p. 11)-. De ahí, pues, la importancia fundamental del enfoque y modelo de la evaluación docente que se pretende adoptar en un país, cuyo propósito nodal es el impulso al desarrollo y calidad de los procesos formativos. Así, en términos generales, siguiendo el análisis de Valdés (2001) e Montenegro (2007), es posible identificar cinco principales modelos de evaluación docente, los cuales son:

- Modelo centrado en el Perfil Profesional. Define competencias profesionales, rasgos personales y/o estándares de desempeño deseables, conforme al perfil docente de un profesor ideal, proyectado por especialistas en la materia o por principios pedagógicos de la teoría educativa, y convertidos en disposición institucional. El «perfil del docente del siglo XXI» de la UNESCO, las «diez nuevas competencias para enseñar», de Philippe Perrenoud, y las «ocho competencias docentes» de la Reforma Integral de la Educación Media Superior (RIEMS), por ejemplo.

- Modelo centrado en los Resultados. El énfasis se concentra en la cantidad y calidad del logro de los aprendizajes alcanzados por sus alumnos, esto es: ¿̇qué aprendieron?, ¿̇cuánto aprendieron? y ¿̇qué tan bien lo aprendieron? Es un modelo de evaluación indirecta del docente. El principio fundamental de este tipo de evaluación lo constituye el reconocimiento de que la función sustantiva de cualquier profesor es la transmisión, enseñanza y/o facilitamiento de los conocimientos propuestos en los planes y programas de estudio, por ende, la ponderación se dirige hacia el grado de consecución de su aprendizaje en los discentes. Verbigracia, la ponderación del Texas Assessment of Academic Skills (TAAS), en Estados Unidos, la valoración de la calidad de los mentores que se deriva de los resultados de la prueba PISA y la Evaluación de las Competencias Básicas de los estudiantes de Colombia.

- Modelo centrado en el Comportamiento Docente. La evaluación se dirige hacia el conjunto de actitudes, aptitudes, disposiciones, acciones, recursos y tiempos que el profesor compromete en el desarrollo cotidiano de sus prácticas docentes. El aspecto nodal aquí es la valoración del tipo de esfuerzo y actuación que el maestro involucra en el proceso de apropiación de los aprendizajes de sus alumnos. El riesgo posible de este modelo es la sobre-valoración del activismo docente, desarticulado de los efectos reales de su labor magisterial, según advierte Montenegro (2007).

- Modelo centrado en la Práctica Reflexiva. La intención central de este tipo de evaluación es que el profesor reflexione, de manera metódica, sobre sus prácticas docentes, a fin de identificar con claridad sus áreas estratégicas de mejoramiento. El enfoque básico del modelo es la auto-evaluación docente y le apuesta al compromiso profesional del mentor para diseñar e instrumentar acciones concretas de transformación de su quehacer formativo, dentro de un proceso sistemático de mejora; sin embargo, al decir de Montenegro (2007), se "carece de los parámetros objetivos para determinar qué tan eficiente es su labor y qué tanto es su mejoramiento" (p. 32). 
- Modelo Integrado. A partir del análisis de los modelos anteriores, este tipo de evaluación define cuatro campos prioritarios de la actuación docente: tales son: el primero, lo constituye el "docente mismo como persona” (Montenegro, 2007, p. 47); el segundo, es el espacio propio donde se desarrolla la relación pedagógica; el tercero, lo representa la institución educativa; y el cuarto, se conforma por el entorno del proceso educativo. En cada uno de estos campos se definen los aspectos básicos de la gestión docente para evaluar.

Por su parte, Stake (2006), más allá de otras propuestas, criterios y disposiciones, reconoce dos principales tipos de evaluación, los cuales, grosso modo, son:

- Evaluación basada en Estándares. Pretende evaluar la "calidad" de un proceso mediante su medición cuantitativa, con el propósito de identificar "objetivamente" los "méritos" y áreas de oportunidad del objeto evaluado, en este caso, el desempeño de los profesores.

- Evaluación Comprensiva. Es interpretación "personal" a partir de la recuperación de la experiencia de los agentes involucrados -profesores, alumnos, directivos, padres de familia-, las preocupaciones que median sus prácticas socioeducativas, los problemas en que se desarrollan y los significados que construyen.

Es pertinente advertir, sin embargo, que Stake (2006) considera importante la conjugación de las visiones, los procedimientos, resultados e interpretación de ambos tipos de evaluación, pues:

\begin{abstract}
En toda reflexión que hagamos contaremos con la ayuda del pensamiento basado en criterios y del interpretativo. Cada vez que evaluemos, necesitaremos tanto una evaluación basada en estándares como una evaluación comprensiva. Juntas, rara vez se suman la una a la otra, pero gracias a las visiones separadas que nos proporcionan, podemos movernos con una mayor sensibilidad, pensar con mayor profundidad, informar con mayor cautela y comprometernos más a fondo con la tarea de representar la calidad. (p. 382)
\end{abstract}

El problema nuclear que evidencian todos estos diferentes modelos de evaluación docente es la inexplicable descontextualización de las acciones formativas realizadas por los profesores, es decir, analizan su perfil profesional sin considerar que tal es el resultado de las estrategias de formación docente, inicial y continua, instrumentadas por el mismo Sistema Educativo; los logros de aprendizaje de sus alumnos, desestimando las condiciones económico-ambientales en donde se generan; su comportamiento didácticopedagógico y profesional en el aula, soslayando las presiones institucionales, sindicales y sociales a las cuales se haya sometido; la auto-reflexión respecto del mejoramiento de su propio desempeño docente, pero, sin reparar en los referentes teórico-prácticos que las dinámicas del entorno institucional le posibilitan; y los distintos campos en donde se concretan las diversas disposiciones magisteriales, aunque desarticuladas de la emergencia histórico-cultural en que acontecen. Cierto, el Modelo Integrado plantea como campo de evaluación el entorno del proceso educativo, pero sólo en la dirección de las acciones transcendentes del marco escolar, promovidas por los mentores en cuanto "contribución al desarrollo social y cultural” del contexto, según explica Montenegro (2007, p. 54), pero, ignora las trascendentes influencias que ejerce el ambiente socio-cultural y políticoeconómico en la resolución de las dinámicas escolares de formación. 
En México, el bajo desempeño de los profesores de Educación Básica tan sólo es el producto directo de la emergente confluencia de una serie diversa de factores, entre los cuales se encuentran: la insuficiente formación profesional docente que se imparte en las Escuelas Normales, según describen explícitamente los estudios del INEE (Santos del Real y Delgado Santoveña, 2015); las acciones de resistencia político-sindicales impulsadas desde el esquema de la ideología del "maestro militante", tanto a nivel de los estudiantes normalistas, como en la dimensión de los mentores en servicio, que se traduce en el rechazo permanente a las transformaciones curriculares, estrategias y recursos de las reformas educativas promovidas por la SEP; y los deficientes procesos de selección al ingreso y promoción en las instituciones formadoras de los profesionales de la educación, así como del reclutamiento institucional a la carrera docente, esto por mencionar algunas de los principales variables al respecto. El desempeño docente, tanto como el fenómeno educativo mismo, no se realizan en el vacío socio-histórico, en el limbo político-cultural, en la oquedad étnico-económica, por el contrario, son determinados por las circunstancias condicionantes de la época y del contexto histórico en que se desarrollan, razón por lo cual, son factores imprescindibles a considerar en sus procesos de evaluación. En sentido estricto, la evaluación docente comporta la evaluación del propio Sistema Educativo que le evalúa.

Empero, pese a la importancia del impacto de estos diversos factores en la resolución del fenómeno educativo contemporáneo y, por ende, del desempeño docente, a causa del consenso generalizado que parece persistir entre los distintos organismos, especialistas y estudios del ámbito internacional, respecto de que "son los docentes y no las escuelas quienes representan el factor institucional más importante que afecta el aprendizaje de los estudiantes" (Hill, 2016, p. s/f), y aún más, en esta misma tendencia, "un currículum es bueno en la medida que cuente con docentes buenos", según sentencia Antonio Fuguet Smith (2006, p. 108), de acuerdo con Bruns y Luque (2014, p. 1), "los gobiernos de todo el mundo, de manera creciente, han puesto bajo la lupa su perfil profesional y estrategias de enseñanza", de donde devienen los afanes institucionales por desarrollar modelos de evaluación docente que posibiliten, al menos, tres acciones fundamentales, estas son: la decantación sistemática del magisterio, la gestión administrativa del arraigo de las políticas que comportan las reformas educativas y, en consecuencia, la elevación de la calidad de los servicios de educación, conforme a los indicadores y estándares prevalecientes en el orden global. El peso específico que los gobiernos le otorgan a cada uno de los factores involucrados y el modo como les articulan en la definición de las políticas educativas, decide el carácter propio del modelo de evaluación docente, diseñado e implantado en cada país.

\section{Antecedentes de la Evaluación Docente en México}

El gobierno mexicano no puede sustraerse a suscribir, producto de la consecuente presión de las diversas instancias internacionales, estas dos tendencias que definen el diseño actual de las políticas educativas, en el orden de las sociedades del siglo XXI, a saber: el recurso institucional de los dispositivos de evaluación y la sistemática depuración, formativolaboral, del magisterio, como factores estratégicos del fortalecimiento de la calidad de la educación formalizada. La articulación emergente de ambas tendencias sustenta la determinación gubernamental de evaluar el desempeño docente, potencial en los futuros 
profesores que se forman y como ejercicio profesional en los mentores ya en servicio; primero, en cuanto ámbito inherente de la expansión de los procesos de evaluación integral del Sistema Educativo - tras haber incursionado ya en la evaluación de los aprendizajes, como también en la evaluación de las escuelas- y segundo, en tanto instrumento oficial que oriente y fundamente la toma de decisiones correspondiente al ingreso, permanencia y promoción de los maestros, en el SPD de México. El desarrollo de la evaluación docente en la Educación Básica de nuestro país, se encuentra asociado íntimamente con la construcción de la experiencia en el campo de la evaluación educativa, y de manera particular, con la evaluación del aprendizaje de los alumnos.

El reconocimiento de la importancia trascendental del profesor en el centro mismo de la disfunción o del éxito de todo un sistema y/o modelo de educación, según advierte Darling-Hammond (2000), predominante en la comprensión socio-educativa contemporánea, durante las últimas tres décadas, no es un fenómeno reciente, para ser precisos, pues, sus fuentes de procedencia se remontan hasta la construcción del primer "Cuestionario de Evaluación de la Docencia por los Alumnos" (CEDA, o TESQ, por sus siglas en inglés: Teacher Evaluation by Students Questionnaire), de Herman Remmers, hacia 1927, para institucionalizarse con el movimiento de rendición de cuentas (accountability), donde se asocia la responsabilidad docente con el logro de los objetivos propuestos, en la década de los años 60’s, de acuerdo con Graciela Cordero Arroyo, et. al. (2016), y se sustenta en las diversas investigaciones desarrolladas durante los últimos seis lustros del siglo XX, en los EUA, como bien documenta Darling-Hammond (2000, p. 32), llegando a la conclusión de que "when aggregated at the state level, teacher quality variables appear to be more strongly related to student achievement than class sizes, overall spending levels, teacher salaries (at least when unadjusted for cost of living differentials), or such factors as the statewide proportion of staff who are teachers". Actualmente, el CEDA se aplica en alrededor del 90\% de las instituciones educativas de este país, al decir de García (2005).

La influencia de la experiencia norteamericana provoca que en la Educación Superior se originen los primeros estudios y propuestas de evaluación docente, en nuestro país, por lo menos dos décadas antes que se instauren los proyectos iniciales en la Educación Básica, como las investigaciones al respecto, de la Universidad Nacional Autónoma de México (UNAM), en los años 70's, y el diseño del primer CEDA mexicano, por el Dr. Ernesto Meneses Morales, de la Universidad Iberoamericana (UIA), aproximadamente hacia el año de 1971, siguiendo la explicación de García Garduño (2005). A partir del análisis factorial de Milton Hildebrand y colaboradores (1973, p. 41), sobre "las características y capacidades de los profesores efectivos", Meneses Morales construye su modelo de CEDA, en función del perfil del maestro universitario que se sustenta en los siguientes rasgos del "buen profesor": a) Transmisión de Conocimientos, b) Comunicación de un Método, y c) Comunicación de su personalidad.

Por su parte, el INEE (s/fa), Banegas y Blanco (2006) parecen concordar con Martínez Rizo y Blanco (2010), respecto a que la experiencia en el diseño e impulso de las políticas de evaluación educativa es un fenómeno por demás reciente, apenas de alrededor de cuatro décadas, en nuestro país, pese a la temprana creación del Instituto Nacional de Psicopedagogía (INP), en el año de 1936, el cual tenía como propósito básico el estudio de los problemas educativos, donde el tema de la evaluación representa un factor insoslayable, sobre todo ante la confluencia emergente del uso estandarizado de las 
pruebas psicométricas en la educación, en primer instancia, y la necesidad de reconocer el grado de avance en el aprendizaje escolar, a fin de legitimar socialmente la pertinencia del recién instaurado modelo de la "Escuela Socialista", por el gobierno del General Lázaro Cárdenas del Río, en segunda instancia. Empero, los esfuerzos del INP no consiguen consolidarse, ni tampoco tienen continuidad institucional, en virtud de lo cual sus posibles aportaciones se pierden de la historia de la evaluación educativa en México, siguiendo el análisis histórico de Martínez Rizo (2001).

De ahí, pues, que la experiencia mexicana en el campo de la evaluación educativa, de acuerdo con Zorrilla y Fernández (2003), el INEE (s/fa), Banegas y Blanco (2006), Martínez Rizo y Blanco (2010), y Cordero, et. al. (2013), se desarrolle hacia el final del siglo XX y principios del siglo XXI, en tres sucesivas etapas, a saber: la primera comprende el periodo de las décadas de los años 70’s y 80's, caracterizada por el interés manifiesto de la SEP, en la construcción de la "estadística educativa" nacional, para lo cual se mejora y sistematiza la información censal al respecto; además de que se crea el Departamento de Estudios Cualitativos de la Educación, en el año de 1972, quien realiza el primer estudio sobre la aptitud para el aprendizaje, en los púberes egresados de la Educación Primaria, del área metropolitana, de la Ciudad de México; este departamento se transforma, luego, en la Subdirección de Evaluación y Acreditación, adscrita a la Dirección General de Planeación Educativa, en 1974, instancia que organiza la primera evaluación de cobertura nacional, con el "Examen de Ingreso a la Secundaria", cuya calificación se realiza en los propios centros escolares, sin considerar todavía la integración de algún tipo de diagnóstico nacional; después, hacia el año de 1984, la subdirección es convertida en la Dirección General de Evaluación (DGE), espacio institucional donde se diseñan y aplican las primeras "pruebas científicas" de rendimiento escolar, en muestras nacionales, según explica García Garduño (2005).²

La primera evaluación de aprendizajes, de acuerdo con Banegas y Blanco (2006), se realiza en el sexenio de José López Portillo, 1976-1982, con el proyecto Evaluación del Rendimiento Académico de los Alumnos de $4^{\circ}$ y $5^{\circ}$ Grados de Educación Primaria, mediante muestras representativas de alumnos, en el ámbito nacional. Para el siguiente sexenio, 1982-1988, el programa sectorial del gobierno de Miguel de la Madrid Hurtado atribuye a los procesos evaluativos la función de determinar el nivel de aprovechamiento escolar, en cada uno de los servicios educativos del país, para lo cual se propone el desarrollo de un "modelo integral de evaluación" que mejore significativamente sus criterios y procedimientos institucionales de operación. En este sentido, la DGE concreta su participación en la Educación Básica y Normal, a través de tres acciones sustantivas, tales son: la primera evaluación de los diez grados de la formación básica -tercero de preescolar, los seis niveles de primaria y los tres grados de secundaria-, la aplicación del "Examen de Ingreso a la Educación Normal" (EIEN) de sostenimiento federal -en 1984, como producto de la elevación formal de los estudios de educación normalista al grado de licenciatura-, y del examen de oposición a los aspirantes de plaza federal, egresados de las normales estatales.

\footnotetext{
${ }^{2}$ Al respecto, es pertinente apuntar que en el año de 1989, la dependencia fue renombrada como Dirección General de Evaluación, Incorporación y Revalidación (DGEIR); después, en 1994, volvió a su nombre anterior, DGE, y para el año 2005 pasa a denominarse ahora como Dirección General de Evaluación de Políticas (DGEP).
} 
En 1989, se diseña y aplica a los alumnos de $6^{\circ}$ grado de primaria, el Instrumento para el Diagnóstico de Alumnos de Nuevo Ingreso a Secundaria (IDANIS); mientras que, hacia el mismo año, el examen de ingreso a las escuelas normales se resignifica para convertirse en Instrumento de Diagnóstico para el Ingreso a Educación Normal (IDCIEN); en el periodo de 1992 a 1995, se delega la instrumentación de esta prueba de evaluación a las entidades federativas y a partir de 1996, es el CENEVAL quien asume la responsabilidad del proceso, a petición de los gobiernos locales.

En el periodo de 1988 a 1994, con el propósito de contrastar el desempeño académico evidenciado durante la fase estudiantil y el desempeño docente que realizan como profesores en servicio, la DGEIR desarrolla el Estudio de Evaluación y Seguimiento de Egresados de Educación Normal. Ahora bien, un fenómeno que conviene destacar, en todo este periodo, es la secrecía de los resultados de las evaluaciones aplicadas y su nulo impacto en la definición de las políticas y programas educativos nacionales, según reconoce la misma SEP (2002a) -pues, pese "al despliegue de esfuerzos realizado, los resultados no impactaron en los responsables de la toma decisiones en materia de política educativa, como tampoco en los elaboradores del currículum ni en los administradores y prestadores directos de los servicios..." y en tanto fueron connotados como "arma política", "los resultados de evaluación se convirtieron en información confidencial” (p. 3).

La segunda etapa se encuentra enmarcada en el lapso de 1990 al año 2000. Los alcances, intervenciones e impactos de la evaluación se potencian en el Sistema Educativo Nacional, durante todo este periodo, a partir del establecimiento de diversos propósitos institucionales, que comprenden desde la acreditación de niveles educativos y la ponderación de los aprendizajes escolares, hasta la revaloración de la función docente, con el sistema de promoción horizontal, incentivos económicos y salariales que comporta la instauración del Programa Nacional de Carrera Magisterial (PNCM), en 1992. De ahí, pues, que se desarrollen diferentes procesos y dispositivos de evaluación educativa, en dos principales ámbitos, a saber: desde el interior se continua con la aplicación del IDANIS, al cual se le suma la evaluación del Factor de Aprovechamiento Escolar, dentro del marco de Carrera Magisterial, y la evaluación del Programa para Abatir el Rezago Educativo (PARE, en 1994 ambos), el Programa de Evaluación de la Educación Primaria (EVEP, 1996) y las Pruebas de Estándares Nacionales de Español y Matemáticas (EN, 1998); mientras que desde el exterior se instrumentan las pruebas internacionales del TIMSS (1995), el Primer Estudio Comparativo y Explicativo (PERCE) del Laboratorio Latinoamericano para la Evaluación de la Calidad de la Educación (LLECE, 1997), de la OREAL-UNESCO, y PISA (2000).

El conjunto de estas diversas acciones de ponderación del logro escolar, en la educación pública de México, fundamenta la creación del Sistema Nacional de Evaluación Educativa (SNEE), hacia la mitad de la década de los años 90's, coordinado por la DGE, cuya finalidad principal es la consolidación y articulación de los programas que en este campo desarrollan las instancias federales y estatales.

Por su parte, aunque de carácter voluntario e individual, el Programa Nacional de Carrera Magisterial representa la primera experiencia de evaluación docente, en el nivel básico de México, y deviene del Acuerdo Nacional para la Modernización de la Educación Básica (ANMEB), suscrito entre el gobierno federal, los gobiernos estatales y el SNTE, dentro del marco de los procesos de la denominada "descentralización educativa". Y al menos en 
la declaración oficial, la evaluación de este programa se concentra en el desempeño docente y el aprovechamiento escolar de sus alumnos. Carrera Magisterial inicia sus procesos en enero de 1993, pero sus efectos se hacen retroactivos al mes de septiembre de 1992. El programa considera cinco niveles de promoción horizontal y estímulo económico (A, B, C, D y E); el estímulo se determina por la relación con las percepciones de la plaza inicial, mientras que ambos se definen por la acumulación de un máximo de 100 puntos, distribuidos en seis factores de evaluación, dependiendo de la vertiente en que participan, tales son: Antigüedad, Grado Académico, Preparación Profesional, Cursos de Actualización, Desempeño Profesional, Aprovechamiento Escolar ( $1^{\text {a }}$ Vertiente), Desempeño Escolar (2a Vertiente) y Apoyo Educativo ( $3^{\text {a }}$ Vertiente).

La evaluación docente, en la lógica institucional de Carrera Magisterial, es secuencial, seriada y completa, es decir, los diferentes niveles sólo pueden ser alcanzados en el orden establecido, tras un periodo obligatorio de permanencia en cada uno de ellos, al mismo tiempo que los seis factores deben ponderarse en cada promoción del postulante, pues, la ausencia de cualquiera de ellos, anula su participación en el proceso respectivo, de acuerdo con la normatividad establecida para tal efecto. Sin embargo, en el comienzo de la aplicación del programa, como estrategia institucional para promover la participación de los maestros y vencer las resistencias de los escépticos, o de los disidentes, a quienes deciden suscribirse al sistema horizontal de incentivos, automáticamente se les otorga un estímulo económico y dependiendo de su grado de estudios se les promueve al nivel B o C, según acusan sus detractores.

Respecto del sistema de promoción horizontal instaurado por el Programa de Carrera Magisterial, quizás conviene advertir que no sustituye, ni desplaza, al Escalafón Vertical, también conocido como "Escalafón Tradicional", dispositivo institucional de ascenso de una categoría inferior a otra categoría superior, de los trabajadores de base de la SEP, instituido en 1930, de acuerdo con Alberto Arnaut Salgado (2013), y cuya última actualización se realiza hacia el año de 1973, con la publicación del "Reglamento de Escalafón de los Trabajadores al Servicio de la Secretaría de Educación Pública”, en el Diario Oficial de la Federación (DOF); ${ }^{3}$ por el contrario, ambos sistemas escalafonarios coexisten y se aplican de manera paralela. Los trabajadores al servicio público del Sistema Educativo Nacional, se convierten en sujetos de derecho escalafonario, una vez cumplidos los seis meses de haber obtenido la asignación de una plaza inicial. El Escalafón Vertical también opera mediante la acumulación de puntos, provenientes de cuatro principales aspectos, los cuales son: Conocimiento (grado académico más superación profesional y personal), Aptitud (eficiencia e iniciativa), Antigüedad (años de servicio), Disciplina y Puntualidad.

En el ámbito de la Educación Media Superior y Superior, con el mismo propósito de promover, diagnosticar y fortalecer la calidad del desempeño y logro de los objetivos de formación de cada uno de estos niveles, mediante el recurso de los dispositivos técnicoprocedimentales de la evaluación educativa, articulando las potencialidades de la

\footnotetext{
${ }^{3}$ La Ley de Inamovilidad de 1930 que norma la evaluación escalafonaria de los profesores de Educación Primaria, se reformula en 1933, con la Ley de Escalafón del Magisterio y posteriormente con la expedición del Reglamento de Escalafón, en 1947, siguiendo a Arnaut (2013).
} 
evaluación interna y externa, en este mismo periodo se constituyen dos instituciones responsables de tal función, a saber: la "Comisión Nacional de Evaluación de la Educación Superior" (CONAEVA) y el "Centro Nacional de Evaluación para la Educación Superior" (CENEVAL). Las principales vertientes de evaluación que se proponen, son: la autoevaluación institucional, la evaluación externa entre pares académicos -bajo cuyo marco se constituyen, en 1991, los Comités Interinstitucionales para la evaluación de la Educación Superior (CIEES) -, y la evaluación integral del sistema de la Educación Superior. Al decir de Rodríguez, et. al. (2009), la CONAEVA, por vía de los hechos, hacia mediados de la década de los años 90's, deja de operar "como instancia de concertación y acuerdo entre el gobierno y las universidades representadas (sic) por la ANUIES” (p. 3).

Por su parte, a recomendación de la Asociación Nacional de Universidades e Instituciones de Educación Superior (ANUIES), en abril de 1993, la Coordinación Nacional para la Planeación de la Educación Superior (CONPES) aprueba la constitución del Centro Nacional de Evaluación para la Educación superior (CENEVAL), en febrero de 1994, como un organismo responsable de contribuir a elevar la calidad de la educación, en el nivel del bachillerato y la Educación Superior, a través de evaluaciones externas, independientes y estandarizadas cuyo propósito nodal es la identificación del desempeño académico y el grado de dominio de los aprendizajes escolares de los jóvenes que ingresan a estos niveles educativos; al respecto es pertinente advertir que las evaluaciones del centro son complementarias, no sustitutivas, de los procesos evaluativos que desarrollan las propias instituciones, con el objeto de acreditar y/o certificar los estudios de sus alumnos.

Las líneas prioritarias de acción del CENEVAL son: por un lado, la elaboración, aplicación y sistematización de resultados de las pruebas de ingreso a la educación media superior y superior - "Examen Nacional de Ingreso a la Educación Media Superior" [EXANI-I], "Examen Nacional de Ingreso a la Educación Superior" [EXANI-II] y "Examen Nacional de Ingreso al Posgrado" [EXANI-III]-; por otro lado, el diseño, instrumentación y procesamiento de los resultados de los "Exámenes Generales para el Egreso de Licenciatura" (EGEL); y por último, la asesoría, capacitación y promoción de las experiencias de evaluación, en estos niveles de educación. En relación con la prueba EGEL es importante señalar que no evalúa conocimientos generales y/o transversales, sino saberes específicos de las diferentes opciones profesionales, de ahí que los distintos exámenes sean independientes entre sí, tanto en la formulación de las preguntas, como en los contenidos a evaluar. El examen propio de los egresados de las licenciaturas para los profesionales de la educación es el EGEL-EDU. En este marco, resulta conveniente señalar que en el año de 1999, la SEP emite el Acuerdo 261 mediante el cual se disponen los criterios y normas de evaluación del aprendizaje de los estudios de la licenciatura para la formación de los profesores de Educación Básica (SEP, 1999).

Un último apunte, oportuno de compartir a modo de cierre del conjunto de fenómenos definitorios de esta etapa, es el hecho de que todavía prevalece en el ánimo de las autoridades educativas mexicanas, una cierta reserva y recelo, cuando no una plena resistencia, para difundir abierta y públicamente los resultados derivados de las pruebas y exámenes de rendimiento académico, tanto nacionales como internacionales, pese al significativo impulso oficial que recibe la evaluación, en cuanto factor estratégico de los propósitos de desarrollo de la educación, en los programas sectoriales de cada gobierno del periodo y, por consecuencia, su emplazamiento en tanto recurso decisivo del esfuerzo 
de promoción, fortalecimiento y mejoramiento de la calidad educativa, mediante la conformación de diversas instancias institucionales, además de la multiplicación y diversificación de los dispositivos instrumentales y/o procedimentales de evaluación.

La tercera fase del desarrollo histórico de la experiencia mexicana en el campo de la evaluación educativa, se inicia en el año 2001, de acuerdo con el INEE (s/fa), Banegas y Blanco (2006), o en el 2002, según propone Cordero, et. al. (2013). Los rasgos fundamentales de la etapa se definen por dos importantes avances institucionales, estos son: en el ámbito político, la evaluación es emplazada como un elemento imprescindible para la planeación de la educación formal y la rendición de cuentas de las autoridades educativas; mientras que en el plano estructural, se establecen los soportes normativos y organizacionales para articular, coordinar y orientar a la diversas instancias de evaluación en el país, así como de vinculación con los organismos internacionales en la materia -la OCDE, la Asociación Internacional para la Evaluación del Logro Educativo (International Association for the Evaluation of Educational Achievement, IEA) y el LLECE, por ejemplo-, siguiendo al INEE (s/fa), Banegas y Blanco (2006).

En función de estos principios rectores se crea el INEE (2002) y, por ende, se impulsa el ulterior fortalecimiento institucional de la reconstitución estratégica del SNEE, como "un conjunto orgánico y articulado de instituciones, procesos, instrumentos, acciones y demás elementos que contribuyen al cumplimiento de sus fines", según se plantea en el Artículo 10, de la ley del instituto (DOF, 2013, p. 13), cuya integración se inicia en la década de los años 90's. Por lo que respecta al desarrollo de la evaluación docente, en el periodo se realizan las siguientes acciones: por un lado, desde el 2004, el CENEVAL diseña e instrumenta los "Exámenes Generales e Intermedios de Conocimientos" para el cuarto y octavo semestre de la Educación Normal -los exámenes intermedios se aplican por primera vez en el 2010, de acuerdo con la SEP (s/f)-; por otro lado, el establecimiento del "Concurso Nacional para el Otorgamiento de Plazas Docentes" (2008), del "Programa de Estímulos a la Calidad Docente" (2008), del "Examen Nacional para la Actualización de los Maestros en Servicio" (ENAMS, 2009) y del Acuerdo para la "Evaluación Universal de Docentes y Directivos en Servicio de Educación Básica” (2011); y por último, la expedición de la "Ley General del Servicio Profesional Docente" (LGSPD, 2013) y la consecuente instauración del "Programa de Promoción en la Función por Incentivos en Educación Básica” (2015).

El concurso para el ingreso al servicio magisterial, los estímulos a la calidad docente, la profesionalización permanente del profesorado y la evaluación universal, derivan de los acuerdos suscritos entre el gobierno federal y el SNTE, en mayo del 2008; los cuales tienen el objeto de fomentar una profunda transformación del Sistema Educativo Nacional, que permita elevar la calidad de la educación mexicana, en el marco de la denominada Alianza por la Calidad Educativa (ACE). Los acuerdos de la ACE se sintetizan en una diversa serie de compromisos institucionales que se agrupan en cinco principales líneas de acción, a saber: primero, modernización de los centros escolares; segundo, profesionalización de los maestros y de las autoridades educativas; tercero, bienestar y desarrollo integral de los alumnos; cuarto, formación integral de los alumnos para la vida y el trabajo; y quinto, evaluar para mejorar. En el acuerdo sobre la profesionalización de los mentores se establece que el ingreso y la promoción de los docentes se realizan por vía del concurso público de oposición, además de estimular el mérito profesional de los maestros, en "función exclusiva de los resultados de logro de sus alumnos" (SNTE, 2008, p. 16); 
mientras que en el compromiso relativo a la evaluación se plantea con toda claridad la articulación del Sistema Nacional de Evaluación, la "evaluación exhaustiva y periódica de todos los actores del proceso educativo” y la definición de los estándares de desempeño, en cada ámbito del fenómeno de la educación formal (SNTE, 2008, p. 24).

Así, pues, el Concurso Nacional para el Otorgamiento de Plazas Docentes se dirige a los egresados de las licenciaturas afines a la educación, que opten por el acceso a una plaza docente definitiva, adicional o, en su defecto, incremento de horas, en los niveles de la Educación Básica. En el 2008, la evaluación la realiza la DGEP, con una prueba que comprende tres áreas sustantivas: contenidos de enseñanza, competencias didácticas y habilidades intelectuales básicas, distribuidas en 80 reactivos. Para el 2009, conforme a los acuerdos de la ACE, se constituye el Órgano de Evaluación Independiente con Carácter Federalista (OEIF), integrado por 72 representantes de la SEP y el SNTE, que tiene como responsabilidad la dictaminación técnica y académica de los criterios de acreditación del concurso, los aspectos de las evaluaciones estatales adicionales, los reactivos de los exámenes y las guías para los sustentantes. A partir de ese año, y a solicitud de la DGEP, el CENEVAL es la instancia encargada de diseñar, coordinar y aplicar los 24 instrumentos estandarizados del "Examen Nacional de Conocimientos y Habilidades Docentes" (ENCHD). ${ }^{4}$ La prueba del CENEVAL consideran cuatro tipos de dominio, tales son: contenidos curriculares, competencias didácticas, habilidades intelectuales específicas $\mathrm{y}$ normatividad, gestión y ética docente, desglosados en 80 reactivos de opción múltiple y 30 reactivos piloteados; el tiempo máximo de resolución del examen es de tres horas, todo esto siguiendo a Santiago, et. al. (2012), Nájera y Mendieta (2014). El diseño del ENCHD carece de un referente preciso sobre el perfil profesional que deben detentar quienes aspiran a incorporarse al magisterio, como bien reconocen Nájera y Mendieta (2014).

El Programa de Estímulos a la Calidad Docente, previsto en los compromisos de la ACE, por su parte, constituye un dispositivo de evaluación indirecta del desempeño magisterial, cuyo propósito básico es el reconocimiento individual y colectivo de los profesores que presentan los mejores logros de aprendizaje de sus alumnos, en las pruebas nacionales "Evaluación Nacional de Logros Académicos en Centros Escolares" (ENLACE), verbigracia-, mediante estímulos salariales, con la intención expresa de promover las prácticas docentes que contribuyan a elevar la calidad educativa. La participación en el programa no es obligatoria y los estímulos se asignan de manera colectiva e individual.

En otro de los acuerdos de la ACE se plantea el compromiso de proporcionar una formación continua a los profesores en servicio, >>orientada hacia la calidad educativa $<<$, por lo que el anterior Programa Nacional para la Actualización Permanente de los Maestros de Educación Básica en Servicio (PRONAP), instaurado en 1994, se transforma en el "Sistema Nacional de Formación Continua y Superación Profesional" (SNFCSP), hacia el año 2008, el cual se acompaña de los ENAMS como un dispositivo oficial de acreditación de los dominios de aprendizaje desarrollados en los trayectos formativos de la práctica docente, diseñados por el sistema, en tres principales áreas, estas son: $e l$

\footnotetext{
${ }^{4}$ En el año del 2009 sólo fueron 17 instrumentos diseñados, pero, para el 2010 se incrementaron seis instrumentos más y en el 2011 se diseña otro para la Educación Inicial, con lo cual se integran 24 exámenes en total.
} 
conocimiento de las disciplinas y de los enfoques de enseñanza, de los procesos de aprendizaje de los niños y jóvenes; el manejo de los materiales educativos; y la comprensión general de los problemas educativos y de la gestión escolar. Una vez más el CENEVAL es la instancia responsable del diseño, validación, seguimiento de la aplicación y calificación de los exámenes. Los ENAMS no son obligatorios, son pruebas estandarizadas, están dirigidos a los profesores de Educación Básica que se desempeñen como docentes frente a grupo, en funciones directivas o como ATP, son específicos para cada curso ofertado por el sistema y tienen como consecuencia dos productos posibles, a saber: un Diploma SEP de acreditación del dominio presentado y un folleto personal de las principales áreas de mejora del sustentante, de acuerdo con SEP (2008) y Santiago y otros (2012).

En el mismo marco de la ACE, la SEP y el SNTE suscriben el Acuerdo para la Evaluación Universal de Docentes y Directivos en Servicio de Educación Básica, con un doble propósito, esto es: por un lado, construir un "diagnóstico integral" de las competencias profesionales de los docentes frente a grupo, directores y ATP, así como del logro académico de sus alumnos; y por otro lado, "focalizar los trayectos de formación continua en las áreas de oportunidad que se detecten con base en sus resultados" (SEP/SNTE, 2011, p. 2); además, se pretende que sus productos orienten la "calidad y pertinencia" de los programas de estudio de la Educación Básica y Normal, así como del diseño y aplicación de políticas educativas eficaces en la consecución de la calidad del Sistema Educativo y del aprendizaje deseable en los estudiantes.

La evaluación es obligatoria para los profesores frente grupo, en funciones directivas y de asesoría técnico-pedagógica, de las «escuelas públicas y privadas»; la periodicidad es trianual, llevándose a cabo el segundo y tercer fin de semana del mes de junio, del año correspondiente. Los resultados de la evaluación se consideran para la acreditación de los factores respectivos de Carrera Magisterial y de los Estímulos a la Calidad Docente, conforme a los lineamientos de cada programa.

La evaluación universal se acompaña de los trayectos de formación continua, principalmente en el campo de las matemáticas, el español, las ciencias, las tecnologías de la información y el inglés, que conforman el SNFCSP; sus resultados son de carácter público y en conjunto con los trayectos particulares que devienen de las áreas de oportunidad identificadas, se informan a las autoridades educativas estatales, al sindicato de los maestros, personal docente, directivo y de supervisión escolar, según explica el Acuerdo establecido entre la SEP y el SNTE. En el diseño de los instrumentos de la evaluación universal participan docentes destacados, directivos, especialistas y asesores académicos de la Educación Básica, así como el INEE, desde luego; con esto "se asegura la pertinencia de los instrumentos de evaluación y se evita el uso unilateral o tendencioso de los mismos", de acuerdo con la SEP (2012, s/p).

Por su parte, a fin de arraigar la institucionalización de la evaluación docente en México, la Reforma Educativa, promovida por el gobierno de Enrique Peña Nieto, en la segunda década del siglo XXI, impulsa cuatro principales acciones, a saber: la consolidación de la autonomía plena del INEE como órgano responsable de coordinar la implementación de las evaluaciones nacionales e internacionales en la educación obligatoria; el fortalecimiento de la estructura organizacional del SNEE; la promulgación de la Ley General del Servicio Profesional Docente (LGSPD) que regula los procesos de ingreso, permanencia, promoción y reconocimiento de los profesores en el SPD; además de la 
implementación sistemática -no exenta de críticas contingencias políticas- de un intrincado, confuso e irrelevante proceso de evaluación docente.

\section{Consideraciones Finales}

En principio, conviene advertir que en una acuciosa revisión de los sistemas educativos de mayor logro académico, encontramos que la evaluación docente no representa el factor nuclear del mejoramiento de la calidad educativa, como se pretende en México, sino más bien un cierto dispositivo institucional de recuperación de información estratégica para reforzar los procesos de formación y desarrollo profesional de los mentores, y por consecuencia lógica, de los servicios públicos de la educación formal. A su vez, la asociación de las acciones evaluativas con los incentivos económicos genera tres tipos de desviaciones educativas, a saber: la corrupción laboral, la simulación docente y la reducción de las prácticas formativas al desarrollo de capacidades para resolver exámenes,

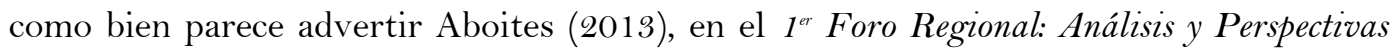
sobre la Reforma Educativa, realizado en la ciudad de Morelia, Michoacán.

La orientación política, la función institucional y los dispositivos procedimentales asignados por la SEP y el INEE, a la evaluación docente, más bien parecen promover el perfil profesional de un "maestro idóneo" capaz de responder a la exigencia de los trayectos evaluativos y de formar alumnos competentes para aprobar exámenes de rendimiento escolar, que a educar ciudadanos, como ya viene sucediendo en nuestro país, de acuerdo con Santiago y otros (2012): "Enseñar para la prueba se ha convertido en una práctica pedagógica generalizada en México. Los directores de escuela, maestros y alumnos consideran que practicar para las pruebas estandarizadas es la mejor estrategia para elevar el logro de los alumnos" (p. 82); incluso, ya en el marco del SPD, los mismos profesores que resultan "no idóneos", conforme a las debilidades de desempeño en la función y/o las áreas de oportunidad en el conocimiento, evidenciadas en los exámenes de permanencia, son "preparados" para acreditar las pruebas subsecuentes, no para potenciar su desarrollo profesional.

A efectos de mejorar los procesos evaluativos de la educación, en México, se constituye un ostentoso, voluminoso y oneroso aparato rector de las estrategias institucionales de evaluación, según previene ya Carlos Ornelas (2013), apenas recién instaurada la plena autonomía del INEE -si "se cumplen esos propósitos [la estructura organizacional dispuesta en el Estatuto Orgánico propuesto por la Junta del Gobierno del instituto], en pocos años tendremos una institución gigantesca, burocrática y pesada, sin rumbo" «y sin eficacia en el desempeño de sus funciones particulares", bien es posible completar el planteamiento del reconocido investigador educativo (s/p)-, pero que, al menos en el ámbito de la evaluación docente, no ha conseguido el establecimiento de un determinado trayecto evaluativo transparente, organizado y equitativo que revalorice la labor magisterial de los profesores y corresponda realmente con las exigencias sociales de su desarrollo profesional y el consecuente mejoramiento de la calidad educativa, siguiendo las conclusiones derivadas de la consulta a los maestros evaluados en el 2015 , realizada por este mismo organismo (INEE, 2016b).

El breve periodo de construcción de la experiencia mexicana en materia de evaluación educativa, en lo general, y de evaluación docente, en lo particular, se caracteriza por la 
excesiva multiplicación y diversificación de las disposiciones, instancias, trayectos, dispositivos procedimentales e instrumentos de evaluación, en el Sistema Educativo Nacional, que lejos de trazar una determinada línea de perfeccionamiento progresivo de las estrategias evaluativas, más bien evidencia rupturas innecesarias, abruptas modificaciones y duplicidad de acciones, sin apenas tiempo suficiente para valorar su verdaderos alcances socio-educativos, impactos institucionales y áreas de mejoramiento técnico, a lo cual deben agregarse las propuestas internacionales de ponderación del logro educativo, como bien se puede apreciar en los cuadros 1, 2 y 3 .

Cuadro 1. Dispositivos de Evaluación Educativa. 1930-1988

\begin{tabular}{|c|c|c|c|c|}
\hline AÑo & $\begin{array}{l}\text { INSTRUMENTO } \\
\text { O PROGRAMA }\end{array}$ & INSTITUCIÓN & А́мвіто & OBJETO DE EVALUACIÓN \\
\hline $\begin{array}{c}1930- \\
1973\end{array}$ & $\begin{array}{l}\text { Escalafón } \\
\text { Vertical }\end{array}$ & SEP-SNTE & Nacional & $\begin{array}{l}\text { Promoción vertical de los } \\
\text { profesores de Educación Básica }\end{array}$ \\
\hline 1971 & CEDA & UIA & Universitario & $\begin{array}{c}\text { Perfil de los profesores } \\
\text { universitários }\end{array}$ \\
\hline 1972 & $\begin{array}{l}\text { Estudio sobre } \\
\text { la Aptitud para } \\
\text { el Aprendizaje }\end{array}$ & $\begin{array}{l}\text { Departamento } \\
\text { de Estudios } \\
\text { Cualitativos de } \\
\text { la Educación }\end{array}$ & Local & $\begin{array}{c}\text { Egresados de la Educación } \\
\text { Primaria }\end{array}$ \\
\hline 1974 & $\begin{array}{l}\text { Examen de } \\
\text { Ingreso a la } \\
\text { Secundaria }\end{array}$ & $\begin{array}{l}\text { Subdirección } \\
\text { de Evaluación } \\
\text { y Acreditación }\end{array}$ & Nacional & $\begin{array}{c}\text { Selección de alumnos para el } \\
\text { ingreso a la Educación Secundaria }\end{array}$ \\
\hline 1976 & Acuerdo 3810 & $\begin{array}{c}\text { Consejo } \\
\text { Nacional } \\
\text { Técnico de la } \\
\text { Educación } \\
\text { (CONALTE) }\end{array}$ & Nacional & $\begin{array}{l}\text { Establecimiento de los } \\
\text { procedimientos de evaluación del } \\
\text { aprendizaje de los alumnos de } \\
\text { Educación Básica y Normal. }\end{array}$ \\
\hline $\begin{array}{c}1976- \\
1982\end{array}$ & $\begin{array}{l}\text { Evaluación del } \\
\text { Rendimiento } \\
\text { Académico de } \\
\text { los Alumnos de } \\
4^{\circ} \text { y } 5^{\circ} \text { Grados } \\
\text { de Educación } \\
\text { Primaria }\end{array}$ & $\begin{array}{l}\text { Subdirección } \\
\text { de Evaluación } \\
\text { y Acreditación }\end{array}$ & Nacional & $\begin{array}{l}\text { Rendimiento escolar de los } \\
\text { alumnos de } 4^{\circ} \text { y } 5^{\circ} \text { grados de } \\
\text { Educación Primaria }\end{array}$ \\
\hline 1978 & Acuerdo 17 & SEP & Nacional & $\begin{array}{c}\text { Establecimiento de las normas } \\
\text { que regulan los procedimientos de } \\
\text { evaluación del aprendizaje, en los } \\
\text { distintos tipo y modalidades de la } \\
\text { educación bajo el control directo } \\
\text { de la SEP }\end{array}$ \\
\hline $\begin{array}{c}1982- \\
1988\end{array}$ & $\begin{array}{c}\text { Evaluación de } \\
\text { los Diez } \\
\text { Grados de la } \\
\text { Educación } \\
\text { Básica }\end{array}$ & DGE & Nacional & $\begin{array}{l}\text { Rendimiento escolar de los } \\
\text { alumnos de Educación Básica }\end{array}$ \\
\hline 1983 & $\begin{array}{l}\text { Instrumento } \\
\text { de Diagnóstico } \\
\text { y Clasificación } \\
\text { para el Ingreso } \\
\text { a Educación } \\
\text { Normal } \\
\text { (IDCIEN) }\end{array}$ & DGE & Nacional & $\begin{array}{l}\text { Proceso de selección de aspirantes } \\
\text { a ingresar a la Educación Normal }\end{array}$ \\
\hline 1984 & $\begin{array}{l}\text { Examen de } \\
\text { Ingreso a la } \\
\text { Educación }\end{array}$ & DGE & Nacional & $\begin{array}{l}\text { Aspirantes a ingresar a las } \\
\text { Escuelas Normales federales }\end{array}$ \\
\hline
\end{tabular}




\begin{tabular}{|c|c|c|c|c|}
\hline AÑo & $\begin{array}{c}\text { INSTRUMENTO } \\
\text { O PROGRAMA }\end{array}$ & INSTITUCIÓN & А́мвіто & OBJETO DE EVALUACIÓN \\
\hline & $\begin{array}{l}\text { Normal } \\
\text { (EIEN) }\end{array}$ & & & \\
\hline 1984 & $\begin{array}{c}\text { Sistema } \\
\text { Nacional de } \\
\text { Investigadores }\end{array}$ & CONACyT & Nacional & $\begin{array}{l}\text { Producción de docentes- } \\
\text { investigadores con el propósito de } \\
\text { otorgar apoyos económicos }\end{array}$ \\
\hline $\begin{array}{c}1982- \\
1988\end{array}$ & $\begin{array}{l}\text { Examen de } \\
\text { Oposición a los } \\
\text { Aspirantes de } \\
\text { Plaza Federal }\end{array}$ & DGE & Nacional & $\begin{array}{l}\text { Egresados de las Escuelas } \\
\text { Normales Estatales }\end{array}$ \\
\hline
\end{tabular}

Fuente: Elaboración propia con base a fuentes oficiales y de investigadores educativos.

Cuadro 2. Dispositivos de Evaluación Educativa. 1989-1999

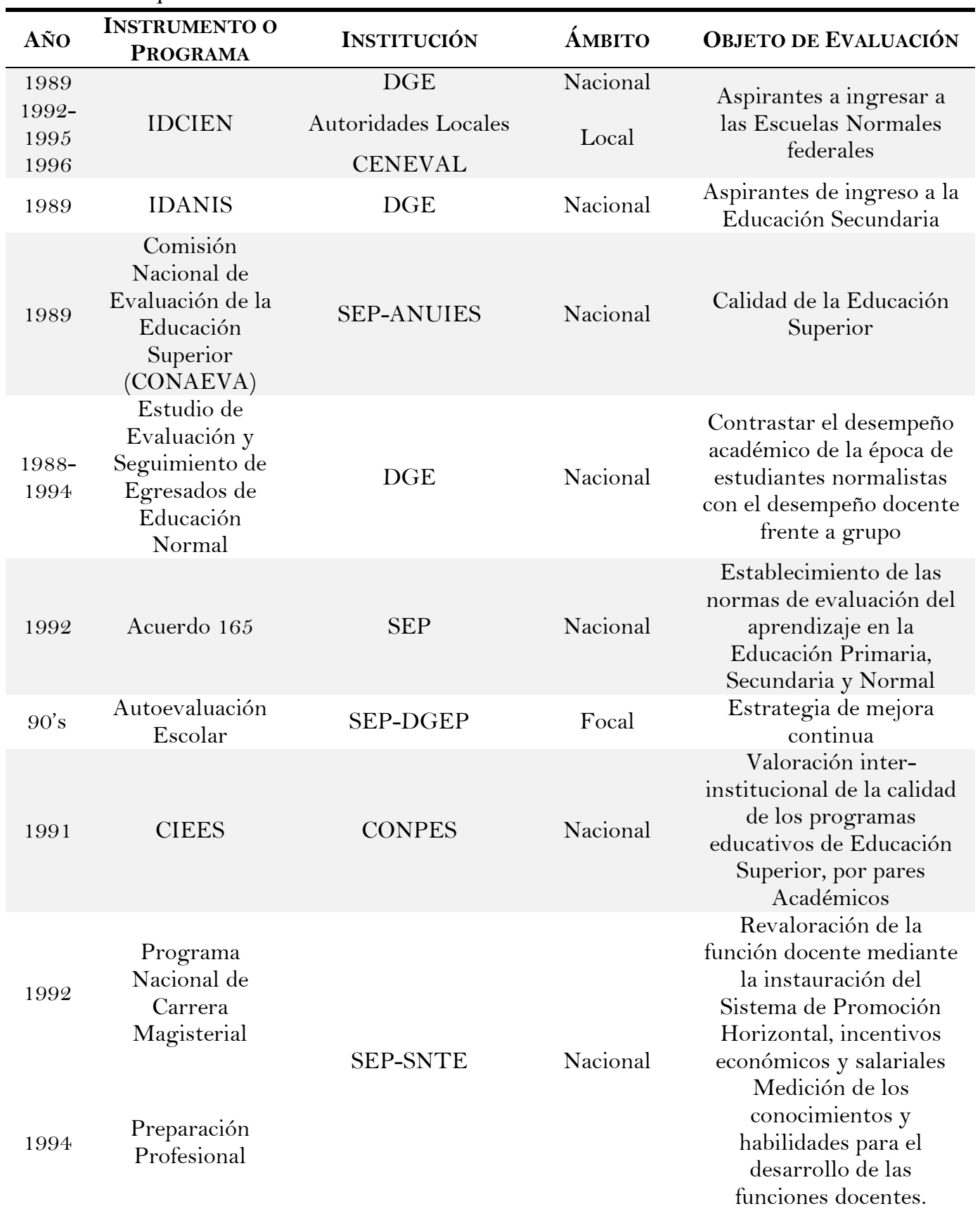




\begin{tabular}{|c|c|c|c|c|}
\hline AÑo & $\begin{array}{c}\text { INSTRUMENTO O } \\
\text { PROGRAMA }\end{array}$ & INSTITUCIÓN & Áмвіто & OBJETO DE EVALUACIÓN \\
\hline & $\begin{array}{l}\text { Aprovechamiento } \\
\text { Escolar }\end{array}$ & & & $\begin{array}{l}\text { Medición del rendimiento } \\
\text { académico de los alumnos } \\
\text { de } 3^{\circ} \text { a } 6^{\circ} \text { de Educación } \\
\text { Primaria y de los tres } \\
\text { grados de la Educación } \\
\text { Secundaria, de los } \\
\text { mentores que participan } \\
\text { en Carrera Magisterial. }\end{array}$ \\
\hline 1994 & $\begin{array}{c}\text { Evaluación } \\
\text { Cualitativa del } \\
\text { PARE }\end{array}$ & $\begin{array}{c}\text { Consejo Nacional de } \\
\text { Fomento Educativo } \\
\text { (CONAFE) }\end{array}$ & Focalizado & $\begin{array}{c}\text { Estudio de unidades } \\
\text { escolares asociadas al } \\
\text { PARE, con el propósito } \\
\text { de estimar los } \\
\text { procedimientos de } \\
\text { implantación y los } \\
\text { cambios posibles } \\
\text { generados por el } \\
\text { Programa, en los Estados } \\
\text { de Guerrero y Oaxaca }\end{array}$ \\
\hline 1994 & Acuerdo 200 & SEP & Nacional & $\begin{array}{c}\text { Establecimiento de las } \\
\text { normas de evaluación del } \\
\text { aprendizaje en la } \\
\text { Educación Primaria, } \\
\text { Secundaria y Normal }\end{array}$ \\
\hline 1994 & Exani-ii & CENEVAL & Nacional & $\begin{array}{l}\text { Identificación del } \\
\text { desempeño académico y el } \\
\text { grado de dominio de los } \\
\text { aprendizajes escolares de } \\
\text { los jóvenes que ingresan a } \\
\text { la EMS y Superior }\end{array}$ \\
\hline 1994 & EGEL-EDU & CENEVAL & Nacional & $\begin{array}{c}\text { Reconocimiento de } \\
\text { saberes profesionales } \\
\text { específicos de los } \\
\text { egresados de la educación } \\
\text { normal }\end{array}$ \\
\hline 1995 & TIMSS & IEA & Internacional & $\begin{array}{c}\text { Dominio de los } \\
\text { conocimientos de } \\
\text { matemáticas y ciencias de } \\
\text { los estudiantes de cuarto } \\
\text { y octavo grado }\end{array}$ \\
\hline 1996 & AEE & Instancias Estatales & Local & $\begin{array}{l}\text { Fortalecimiento de las } \\
\text { tareas evaluativas en las } \\
\text { entidades federativas }\end{array}$ \\
\hline 1996 & $\begin{array}{l}\text { Comité } \\
\text { Interestatal } \\
\text { Técnico de } \\
\text { Evaluación } \\
\text { (CTIE) }\end{array}$ & DGE & Nacional & $\begin{array}{l}\text { Concertación federal y } \\
\text { estatal de las AEE }\end{array}$ \\
\hline 1996 & EVEP & $\mathrm{DGE} / \mathrm{CONAFE}$ & Nacional & $\begin{array}{l}\text { Conformación de series } \\
\text { históricas sobre el logro } \\
\text { educativo en la Educación } \\
\text { Primaria y, al propio } \\
\text { tiempo, consolidación de } \\
\text { AEE. }\end{array}$ \\
\hline 1997 & $\begin{array}{l}\text { Evaluaciones } \\
\text { Cualitativas }\end{array}$ & DGE & Nacional & $\begin{array}{c}\text { Estudio de las dinámicas } \\
\text { escolares de gestión } \\
\text { educativa y práctica } \\
\text { pedagógica, en la }\end{array}$ \\
\hline
\end{tabular}




\begin{tabular}{|c|c|c|c|c|}
\hline AÑo & $\begin{array}{c}\text { INSTRUMENTO O } \\
\text { PROGRAMA } \\
\end{array}$ & INSTITUCIÓN & Áмвіто & OBJETO DE EVALUACIÓN \\
\hline & & & & $\begin{array}{l}\text { Educación Primaria y } \\
\text { Secundaria, con el fin de } \\
\text { explicar el logro } \\
\text { académico }\end{array}$ \\
\hline 1997 & PERCE & & & $\begin{array}{l}\text { Aprendizaje de los } \\
\text { estudiantes de 3er y 4to } \\
\text { grado de Educación } \\
\text { Primaria, en el campo de } \\
\text { la lectura y la matemática }\end{array}$ \\
\hline 2006 & SERCE & $\begin{array}{c}\text { LLECE- } \\
\text { OREALC/UNESCO }\end{array}$ & Internacional & $\begin{array}{c}\text { Aprendizaje del lenguaje } \\
\text {-lectura y escritura- y la } \\
\text { matemática en }\end{array}$ \\
\hline 2013 & TERCE & & & $\begin{array}{c}\text { estudiantes de } 3 \text { er y } 6 \text { to } \\
\text { de Educación Primaria, } \\
\text { así como de ciencias } \\
\text { naturales, en este último } \\
\text { nivel }\end{array}$ \\
\hline 1998 & $\begin{array}{l}\text { Estándares } \\
\text { Nacionales }\end{array}$ & DGE & Nacional & $\begin{array}{c}\text { Medición del grado de } \\
\text { desarrollo de las } \\
\text { habilidades para la } \\
\text { comprensión lectora y la } \\
\text { resolución de problemas } \\
\text { matemáticos }\end{array}$ \\
\hline $\begin{array}{l}1998 \\
2000 \\
2003 \\
2006 \\
2009 \\
2012 \\
2015\end{array}$ & PISA & OCDE & Internacional & $\begin{array}{l}\text { Competencias básicas } \\
\text { para la vida y el trabajo } \\
\text { de los jóvenes de } 15 \text { años }\end{array}$ \\
\hline 1999 & Acuerdo 261 & SEP & Nacional & $\begin{array}{l}\text { Criterios y normas de } \\
\text { evaluación del aprendizaje } \\
\text { de los estudios de } \\
\text { licenciatura para la } \\
\text { formación de los } \\
\text { profesores de Educación } \\
\text { Básica }\end{array}$ \\
\hline
\end{tabular}

Fuente: Elaboración propia con base a fuentes oficiales y de investigadores educativos.

Cuadro 3. Dispositivos de Evaluación Educativa. 2000-2015

\begin{tabular}{|c|c|c|c|c|}
\hline AÑo & $\begin{array}{c}\text { INSTRUMENTO } \\
\text { O PROGRAMA }\end{array}$ & INSTITUCIÓN & А́мвіто & OBJETO DE EVALUACIÓN \\
\hline 2000 & COPAES & 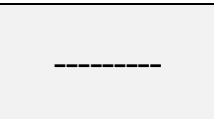 & Nacional & $\begin{array}{c}\text { Acreditación de órganos } \\
\text { certificadores de programas } \\
\text { académicos }\end{array}$ \\
\hline 2001 & $\begin{array}{l}\text { Evaluación del } \\
\text { Programa de las } \\
\text { Escuelas de } \\
\text { Calidad (PEC) }\end{array}$ & $\begin{array}{l}\text { DGE- } \\
\text { Coordinación } \\
\text { Nacional del } \\
\text { PEC-AEE }\end{array}$ & Nacional & $\begin{array}{l}\text { Valorar el impacto del PEC en los } \\
\text { centros educativos, respecto del } \\
\text { logro académico, las prácticas } \\
\text { pedagógicas, la rendición de cuentas } \\
\text { y la autoevaluación }\end{array}$ \\
\hline 2010 & $\begin{array}{l}\text { Exámenes } \\
\text { Generales e } \\
\text { Intermedios de } \\
\text { Conocimientos }\end{array}$ & CENEVAL & Nacional & $\begin{array}{l}\text { Diagnóstico general de la formación } \\
\text { docente } \\
\text { Diagnóstico intermedio de la } \\
\text { formación docente }\end{array}$ \\
\hline
\end{tabular}




\begin{tabular}{|c|c|c|c|c|}
\hline AÑo & $\begin{array}{l}\text { INSTRUMENTO } \\
\text { O PROGRAMA }\end{array}$ & INSTITUCIÓN & А́мвіто & OBJETO DE EVALUACIÓN \\
\hline 2005 & Excale & INEE & Nacional & $\begin{array}{l}\text { Valoración del grado en que los } \\
\text { alumnos alcanzan los aprendizaje } \\
\text { establecidos en los planes y } \\
\text { programas de estúdio }\end{array}$ \\
\hline 2006 & Enlace & SEP & Nacional & $\begin{array}{l}\text { Nivel de dominio en español, } \\
\text { matemáticas y una tercera } \\
\text { asignatura rotativa anualmente, } \\
\text { conforme a los planes y programas } \\
\text { oficiales de estudio, en Educación } \\
\text { Básica; dominio de las habilidades } \\
\text { para la vida en español, matemáticas } \\
\text { y las competencias establecidas en la } \\
\text { RIEMS, el bachillerato }\end{array}$ \\
\hline 2006 & $\begin{array}{c}\text { Estudios sobre } \\
\text { las Condiciones } \\
\text { de la Oferta } \\
\text { Educativa }(\mathrm{COE})\end{array}$ & INEE & Nacional & $\begin{array}{l}\text { Valoración de los recursos y } \\
\text { procesos de las escuelas de } \\
\text { Educación Básica }\end{array}$ \\
\hline 2008 & $\begin{array}{l}\text { Concurso } \\
\text { Nacional para el } \\
\text { Otorgamiento de } \\
\text { Plazas Docentes }\end{array}$ & DGEP & Nacional & $\begin{array}{l}\text { Selección de los profesionales de la } \\
\text { educación que opten por el acceso a } \\
\text { una plaza docente definitiva, } \\
\text { adicional o incremento de horas en } \\
\text { Sistema Educativo Nacional }\end{array}$ \\
\hline 2008 & $\begin{array}{l}\text { Programa de } \\
\text { Estímulos a la } \\
\text { Calidad Docente }\end{array}$ & SEP & Nacional & $\begin{array}{l}\text { Reconocimiento de los maestros de } \\
\text { Educación Especial y Básica cuyos } \\
\text { alumnos presentan alto desempeño } \\
\text { escolar }\end{array}$ \\
\hline 2009 & $\begin{array}{c}\text { Sistema Nacional } \\
\text { de Acreditación } \\
\text { de Centros } \\
\text { Escolares de } \\
\text { Educación Básica } \\
\text { (SNACEEB) }\end{array}$ & DGEP & Nacional & $\begin{array}{c}\text { Ponderación de la calidad de los } \\
\text { ámbitos, componentes y funciones de } \\
\text { los centros escolares de la Educación } \\
\text { Básica }\end{array}$ \\
\hline $\begin{array}{l}2009 \\
2012\end{array}$ & $\begin{array}{l}\text { ENCHD } \\
\text { ENCHCD }\end{array}$ & CENEVAL & Nacional & $\begin{array}{c}\text { Valoración de las habilidades } \\
\text { docentes para la enseñanza, en la } \\
\text { educación obligatoria }\end{array}$ \\
\hline 2009 & ENAMS & CENEVAL & Nacional & $\begin{array}{l}\text { Acreditación de los dominios de } \\
\text { aprendizaje desarrollados en los } \\
\text { trayectos formativos de la práctica } \\
\text { docente, diseñados por el Sistema } \\
\text { Educativo Nacional }\end{array}$ \\
\hline 2011 & $\begin{array}{l}\text { Evaluación } \\
\text { Universal de } \\
\text { Docentes y } \\
\text { Directivos en } \\
\text { Servicio de } \\
\text { Educación Básica }\end{array}$ & INEE & Nacional & $\begin{array}{c}\text { Construcción de un diagnóstico } \\
\text { integral de las competencias } \\
\text { docentes frente a grupo, directivos y } \\
\text { ATP, así como del logro académico } \\
\text { de sus alunos }\end{array}$ \\
\hline 2014 & $\begin{array}{l}\text { ELSEN } \\
\text { ELCE } \\
\text { EDC }\end{array}$ & INEE & Nacional & $\begin{array}{c}\text { Identificación del grado de dominio } \\
\text { de los aprendizajes escolares, en los } \\
\text { estudiantes de la educación } \\
\text { obligatoria, conforme a los planes y } \\
\text { programas de estúdio } \\
\text { Identificación del logro académico de } \\
\text { los alunos } \\
\text { Reconocimiento de aprendizajes } \\
\text { clave } \\
\text { Identificación de aprendizajes clave } \\
\text { en los campos formativos del }\end{array}$ \\
\hline
\end{tabular}




\begin{tabular}{|c|c|c|c|c|}
\hline AÑo & $\begin{array}{l}\text { INSTRUMENTO } \\
\text { O PROGRAMA }\end{array}$ & INSTITUCIÓN & А́мвіто & OBJETO DE EVALUACIÓN \\
\hline & & & & $\begin{array}{c}\text { lenguaje y comunicación, además de } \\
\text { matemáticas }\end{array}$ \\
\hline 2014 & $\begin{array}{l}\text { Concursos de } \\
\text { Ingreso al SPD }\end{array}$ & INEE & Nacional & $\begin{array}{l}\text { Valoración de la suficiencia en el } \\
\text { dominio de los conocimientos y } \\
\text { capacidades para el desempeño } \\
\text { docente, en los profesores que se } \\
\text { incorporan al SPD }\end{array}$ \\
\hline 2015 & $\begin{array}{l}\text { Evaluación del } \\
\text { Desempeño } \\
\text { Docente }\end{array}$ & INEE & Nacional & $\begin{array}{l}\text { Identificación de la idoneidad de los } \\
\text { maestros en servicio }\end{array}$ \\
\hline 2015 & $\begin{array}{l}\text { Programa de } \\
\text { Promoción en la } \\
\text { función por } \\
\text { Incentivos en } \\
\text { Educación Básica }\end{array}$ & INEE & Nacional & $\begin{array}{c}\text { Reconocimiento a profesores de alto } \\
\text { desempeño y resultados } \\
\text { sobresalientes en las evaluaciones } \\
\text { adicionales }\end{array}$ \\
\hline
\end{tabular}

Fuente: Elaboración propia con base a fuentes oficiales y de investigadores educativos.

En síntesis, los diferentes dispositivos institucionales de la evaluación educativa, sobre los cuales se viene construyendo la experiencia mexicana en este campo, pueden agruparse en tres principales estrategias gubernamentales, estas son: por un lado, el establecimiento de políticas, programas y acuerdos secretariales que fundamentan, orientan y regulan los diversos procesos evaluativos, en los distintos niveles del Sistema Educativo Nacional; por otro lado, la conformación de instancias, dependencias, organismos, instituciones y sistemas de carácter federal y/o estatal, responsables del diseño, validación y aplicación de los instrumentos de evaluación, así como de la organización, procesamiento y difusión de sus resultados; y por último, la construcción de estudios, diagnósticos y recursos instrumentales de valoración del desempeño de los servicios de la educación formal, con el objeto de promover el mejoramiento de su calidad académica. Al decir de Hugo Aboites (2012), en casi 25 años se han aplicado más de 110 millones de exámenes estandarizados a niños, jóvenes, profesores y escuelas. Incluso, en esta compulsiva tendencia a evaluar todo, las propias disposiciones de evaluación también son evaluadas por diferentes agentes internacionales y nacionales, como la implementada por la Research and Development Corporation (RAND) al Programa de Carrera Magisterial, los análisis y valoraciones de la OREALC/UNESCO a la Evaluación del Desempeño de Docentes, Directivos y Supervisores de la Educación Básica y Media Superior, del 2015-2016, las revisiones generales de los equipos de la OCDE a los procesos evaluativos de nuestro país y el Estudio de Validación de las pruebas Enlace y Excale, realizado por el equipo que coordina Felipe Martínez Rizo (2015), por ejemplo; pero que, en su conjunto, no han logrado propiciar la elevación de la calidad de los servicios educativos en el país y mucho menos reposicionar al Sistema Educativo Nacional en el ranking de las evaluaciones internacionales.

\section{Referencias}

Aboites, H. (2012). La disputa por la evaluación en México: Historia y futuro. El Cotidiano, Revista de la Realidad Mexicana Actual,176(noviembre-diciembre), 1-25.

Banegas, I. y Blanco Bosco, E. (2006) Políticas y sistemas de evaluación educativa en México. Avances, logros y desafios. Ciudad de México: INEE. 
Beck, U. (2007) Teoría de la sociedad del riesgo. En A. Giddens et. al. (Eds.), Las consecuencias perversas de la modernidad (pp. 201-222). Barcelona: Anthropos.

Bruns, B. y Luque, J. (2014). docentes excelentes: cómo mejorar el aprendizaje en América Latina y el Caribe Resumen. Washington, DC: Banco Mundial.

Cordero Arroyo, G. (2013). La evaluación docente en Educación Básica en México: panorama y agenda pendiente. Sinéctica, Revista Electrónica de Educación, 41.

Darling-Hammond, L. (2000). Teacher quality and student achievement: A Review of state policy rvidence. Education Policy Analysis Archives, 8(1),1-44. https://doi.org/10.14507/epaa.v8n1.2000

Fuguet Smith, A. (2006) Educación en Canadá: Protocolos y elementos de reflexión para el desarrollo curricular. Caracas: Colecciones Estudios Canadienses.

García Garduño, J. M. (2005). el avance de la evaluación en México y sus antecedentes. Revista Mexicana de Investigación Educativa, 10(27), 1275-1283.

Hanson, F. A. (1994). Testing testing: social consequences of the examined life. Berkeley, CA: University of California Press.

Hill, H. C. (2016). Evaluación de maestros en Estados Unidos: Un caso de estudio. Recuperado de http://politikon.es/2016/04/19/18152/\#

INEE. (2006). Los cuatro primeros años. Avances y desafíos. Ciudad de México: INEE.

INEE. (2007). Plan de Desarrollo del Sistema Nacional de Indicadores Educativos de México, 2007-2014. Ciudad de México: INEE.

INEE. (2013). Estatuto Orgánico del Instituto Nacional para la Evaluación de la Educación. Ciudad de México: DOF.

INEE. (2015a). Plan Nacional para la Evaluación de los Aprendizajes (PLANEA). Ciudad de México: INEE.

INEE. (2016a). Criterios Técnicos y de Procedimientos para el Análisis de los Instrumentos de Evaluación, el Proceso de Calificación y la Emisión de Resultados. Ciudad de México: DOF.

INEE. (2016b). Evaluación del Desempeño desde la Experiencia de los Docentes. Consulta con Docentes que Participaron en la Primera Evaluación del Desempeño 2015. Ciudad de México: INEE.

INEE. (2017a). La Evaluación del Desempeño, 2017. Ciudad de México: INEE.

INEE. (2017b). La Educación Obligatoria en México. Informe 2017. Ciudad de México: INEE.

INEE. (s/fa). Breve recorrido por la evaluación de la Educación Básica en México. Ciudad de México: INEE.

INEE. (s/fb). Evaluación docente. Ciudad de México: INEE.

Landínez, D. (2011). Resistiendo al control. ¿Es posible una ética de la resistencia?. Saga, Revista de Estudiantes de Filosofía, 22, 37-46.

Martínez Rizo, F. (2001). Evaluación educativa y pruebas estandarizadas. Elementos para Enriquecer el Debate. Revista de la Educación Superior, 120(30), 1-12.

Martínez Rizo, F. (2013). El Futuro de la Evaluación Educativa. Sinéctica, Revista Electrónica de Educación, 40.

Martínez Rizo, F. (2015a). Las Pruebas EXCALE para Educación Básica. Una Evaluación para el Instituto Nacional para la Evaluación de la Educación. Ciudad de México: INEE. 
Martínez Rizo, F. (2015b) Las Pruebas ENLACE y EXCALE. Ciudad de México: INEE

Martínez Rizo, F. y Blanco, E. (2010). La Evaluación Educativa en México: Experiencias, Avances y Desafíos. En A. Arnaut y S. Giorguli (Coords.), Los Grandes Problemas de México. VII. Educación (pp. 89-124). Ciudad de México: El Colegio de México.

Montenegro Aldana, I. A. (2007). Evaluación del desempeño docente. fundamentos, modelos $e$ instrumentos. Bogotá: Cooperativa Editorial Magisterio.

Moreno Olivos, T. (2011). La cultura de la evaluación y la mejora de la escuela. Perfiles Educativos, 23(131), 116-130.

Santiago, P., McGregor, I., Nusche, D., Ravela, P. y Toledo, D. (2012). Revisiones de la OCDE sobre la evaluación en educación. Ciudad de México: OCDE.

Santos del Real, A. y Delgado Santoveña, A. (Coords.) (2015). Los docentes en México. Informe 2015. Ciudad de México: INEE.

Santos Guerra, M. A. (2002). Una flecha en la diana. la evaluación como aprendizaje. Andalucía Educativa, 34, 7-9.

Santos Guerra, M. A. (2003a). Dime cómo evalúas y te diré qué tipo de profesional y de persona eres. Revista Enfoques Educacionales, 5(1), 69-80.

Santos Guerra, M. A. (2003b). La evaluación como aprendizaje. Una flecha en la diana. Madrid: Narcea.

SEP. (1999). Acuerdo Número 261 por el que se Establecen Criterios y Normas de Evaluación del Aprendizaje de los Estudios de Licenciatura para la Formación de Profesores de Educación Básica. Ciudad de México: DOF.

SEP. (2002a). La Experiencia de la Dirección General de Evaluación en la Educación Básica y Normal. 30 Años de Medición del Logro Educativo. Ciudad de México: SEP.

SEP. (2002b). Decreto por el que se Crea el Instituto Nacional para la Evaluación de la Educación. Ciudad de México: DOF.

SEP. (2008). Folleto Informativo. Exámenes Nacionales para la Actualización de los Maestros en Servicio (ENAMS) La Asesoría Académica en Educación Básica. Ciudad de México: CENEVAL.

SEP. (2011). OCDE Revisión de los Marcos de Valoración y de Evaluación para Mejorar los Resultados Escolares. Informe de las Prácticas de la Evaluación de la Educación Básica en México. 2010. Ciudad de México: SEP.

SEP. (2013a). Lineamientos que Regulan el Programa de Estímulos a la Calidad Docente. Ciudad de México: SEP.

SEP. (2013b). Ley del Instituto Nacional para la Evaluación de la Educación. Ciudad de México: INEE.

SEP. (2015). Etapas, Aspectos, Métodos e Instrumentos. Proceso de Evaluación del Desempeño Docente. Educación Básica. Ciclo Escolar 2015-2016. Ciudad de México: SEP.

SEP. (2017). Etapas, aspectos, métodos e instrumentos. Proceso de evaluación del desempeño docente. Educación Básica. Ciclo Escolar 2017-2018. Ciudad de México: SEP.

SEP/SNTE. (2011). Acuerdo para la evaluación universal de docentes y directivos en servicio de Educación Básica. Ciudad de México: SEP/SNTE.

SNTE. (2008). Alianza por la calidad de la educación. Ciudad de México: SNTE.

SNTE. (2015). La evaluación del desempeño docente. Ciudad de México: SNTE.

Stake, R. E. (2006). Evaluación Comprensiva y Evaluación Basada en Estándares. Barcelona: Graó. 
Valdés Veloz, H. (2001). la evaluación del desempeño del docente: un pilar del sistema de evaluación de la calidad de la educación en Cuba. Recuperado de http://www.opech.cl/bibliografico/calidad_equidad/Valdes\%20-

\%20Evaluacion\%20del\%20desempeno\%20del\%20docente.pdf

Valdés Veloz, H. (2006a). Desempeño del maestro y su evaluación. La Habana: Ediciones Pueblo y Educación.

Valdés Veloz, H. (2006b, julio). Los docentes en el sistema educativo cubano: análisis de su carrera, desarrollo profesional y evaluación de su desempeño. Ponencia presentada en el Encuentro Internacional sobre Evaluación, Carrera y Desarrollo Profesional Docente, Universidad Cardenal Silva Henríquez de Chile, Santiago de Chile.

Vidal, R. (2009). ¿Enlace, Exani, Excale o PISA?. Ciudad de México: CENEVAL.

\section{Breve CV del autor}

\section{Francisco Guzmán Marín}

Profesor-Investigador de la Universidad Pedagógica Nacional (UPN). Doctor en Ciencias Sociales, Área de Concentración: Cultura Política y Relaciones de Poder por la UAM-X. Posee una maestría en Filosofía de la Cultura por la UMSNH. Es Licenciado en Matemáticas por la UAT y Profesor de Educación Primaria por la ENR "Vasco de Quiroga". Ha trabajado 15 años como profesor de Educación Primaria y 18 años como profesor de Educación Superior. ORCID ID: O000-0001-94337680. Email: coraxthelastone@hotmail.com 